\title{
Histology and Scanning Electron Microscopy of Lymphoid Tissue in Jejunal Peyer's Patches in Goat
}

\author{
V. R. Indu*, K. M. Lucy, N. Ashok and S. Maya \\ Department of Veterinary Anatomy \& Histology, College of Veterinary and Animal Sciences, \\ Mannuthy, Kerala, India \\ *Corresponding author
}

\section{A B S T R A C T}

\section{Keywords}

Peyer's patches, Jejunum, Lymphoid tissue, Goats

Article Info

Accepted:

17 October 2020

Available Online:

10 November 2020
The lymphoid tissue in jejunal Peyer's patches (JPP) in goats was studied in six apparently healthy male goats of six months of age. It was observed that in the JPP submucosal lymphoid nodules were seen with a corona and subepithelial dome region over it, an internodular region and the overlying follicle associated epithelium. The number of lymphoid nodules counted per field under low power magnification of microscope was $2.17 \pm 0.17$. The average diameter of the lymphoid nodules was $845.67 \pm 1.61 \mu \mathrm{m}$ and the lymphocyte count in it was $28358.33 \pm 119.32$. Height of the dome of each lymphoid nodule measured $143.83 \pm 1.3 \mu \mathrm{m}$ and the FAE covering it was $32.41 \pm 48.92 \mu \mathrm{m}$ long at six months of age in goats. It was concluded that the lymphoid nodules in jejunal Peyer's patches remained active and continued to produce lymphocytes suggesting that it was a secondary lymphoid organ in contrast to the ileal Peyer's patches which are primary lymphoid organs.

\section{Introduction}

Peyer's patches (PP) form a part of the gut associated (GALT) seen in small and large intestines and are named after the $17^{\text {th }}$ century Swiss anatomist, Johann Conrad Peyer who first described them as "intestinal glands," in sheep in 1677 (Tenorio and Pabst, 2006).

A thorough knowledge of the morphology and morphometry of GALT is very essential in elucidating its role in disease pathogenesis and gut immunology.

\section{Materials and Methods}

For the present study six apparently healthy male goats of age six months, sold for slaughter from the University Sheep and Goat Farm, Mannuthy were used. The small intestines were carefully separated out, straightened, opened at the side of mesenteric attachment and cleaned. Tissue pieces were collected from the region of jejunum and fixed in 10 per cent neutral buffered formalin. The materials were processed routinely to obtain 5-6 $\mu \mathrm{m}$ thick serial paraffin sections and were stained by Haematoxylin and Eosin 
(Luna, 1968) and Gomori's rapid one step trichrome method for collagen fibres (Luna, 1968). The micrometry was done in the histological sections in six randomly selected fields under high or low power magnifications using an ocular micrometer. And the data collected were analysed statistically as per the methods described by Snedecor and Cochran (1994) using software (SPSS version, 21).

For scanning electron microscopy (SEM) samples collected were fixed in 2.5 per cent gluteraldehyde in $0.1 \mathrm{M}$ phosphate buffer (PBS) (pH 7.2) for $24 \mathrm{~h}$ at $4^{\circ} \mathrm{C}$ and post fixed in two per cent aqueous osmium tetroxide for four hours. Thereafter dehydrated in series of ascending grades of alcohol and dried to critical point drying with CPD unit. The processed samples were mounted over the stubs with double sided carbon conductivity tape and a thin layer of gold coat on the samples were done by using an automated sputter-coater (Model- JEOL JFC-1600) for three minutes and scanned under Scanning Electron Microscope (SEM-Model: JEOLJSM 5600) at required magnifications as per the standard procedures (Bozzola and Russel, 1998) at RUSKA Labs, College of Veterinary Science, SVVU, Rajendranagar, Hyderabad, Andhra Pradesh.

\section{Results and Discussion}

GALT in the small intestine was composed of aggregates of lymphoid nodules seen grossly as elevations in the mucosa, which were further distinguishable into discrete Peyer's patch (PP) in jejunum called jejunal Peyer's patch (JPP) and continuous PP seen in the terminal part of the jejunum as reported by Getty (2012) in horse. The histological compartments of the JPP were the submucosal lymphoid nodules with a corona or mantle that capped it, the subepithelial dome region over the nodules, an internodular region and the overlying follicle associated epithelium (FAE) (Fig. 1). The lymphoid nodules with germinal centre were pear shaped and arranged in three to four rows separated by wide internodular areas similar to the observations made by Saw et al., (2005) and Tenorio and Pabst (2006) in bovines (Fig. 2). The number of lymphoid nodules counted per field under low power magnification of microscope was $2.17 \pm 0.17$. The average diameter of the lymphoid nodules was $845.67 \pm 1.61 \mu \mathrm{m}$ and the lymphocyte count in it was $28358.33 \pm 119.32$.

The domes in JPP were relatively larger and cylindrical with conical upper ends while dome crypts were oval or kidney shaped in cross section as reported by Shukla and Singh (1999) in dogs and Saw et al., (2005) in calves. The lymphocytes within the dome were tightly packed, relatively larger with large nuclei and stained lighter than the distinct corona of lymphoid nodules below it. Some crypts were also seen in the dome with many empty vacuoles in the cytoplasm of enterocytes. Height of the dome of each lymphoid nodule measured $143.83 \pm 1.3 \mu \mathrm{m}$ at six months. Torres (1981) found that in JPP of adult gnotobiotic calves, average height of dome of each lymphoid follicle was $250 \mu \mathrm{m}$.

The epithelium covering the domes consisted of a single layer of thinner and shorter columnar cells which separated the lymphoid tissue from the intestinal lumen. The nuclei of these cells were found at various levels as compared to the enterocytes in which the nucleus was situated at the base of cells. The cells in FAE were not vacuolated and goblet cells were absent in contrast to the highly vacuolated absorptive intestinal cells with numerous goblet cells. These observations concur with the earlier reports of Liebler $e t$ al., (1988) in cattle, Aleksandersen et al., (1991) in sheep and Shukla and Singh (1999) in dogs. The height of FAE in JPP measured $32.41 \pm 48.92 \mu \mathrm{m}$. Similar reports regarding 
micrometry of FAE in JPP of goats are not available for comparison.

In the present study the lymphoid nodules in JPP remained active and continued to produce lymphocytes. The persistence of jejunal Peyer's patches, in contrast to the early involution of the ileal Peyer's patches as reported by Reynolds and Morris (1983) could be due to the function of JPPs in generation of $\operatorname{IgA}$ secreting plasma cell precursors. Further, in JPP, the prevalence of internodular areas with T-cells needed for IgM-IgA switch, supported this idea (Larsen and Landsverk, 1985).

Fig.1 C.S. of jejunal Peyer's patches showing lymphoid nodules (1 month). Gomori's one step trichrome x 100
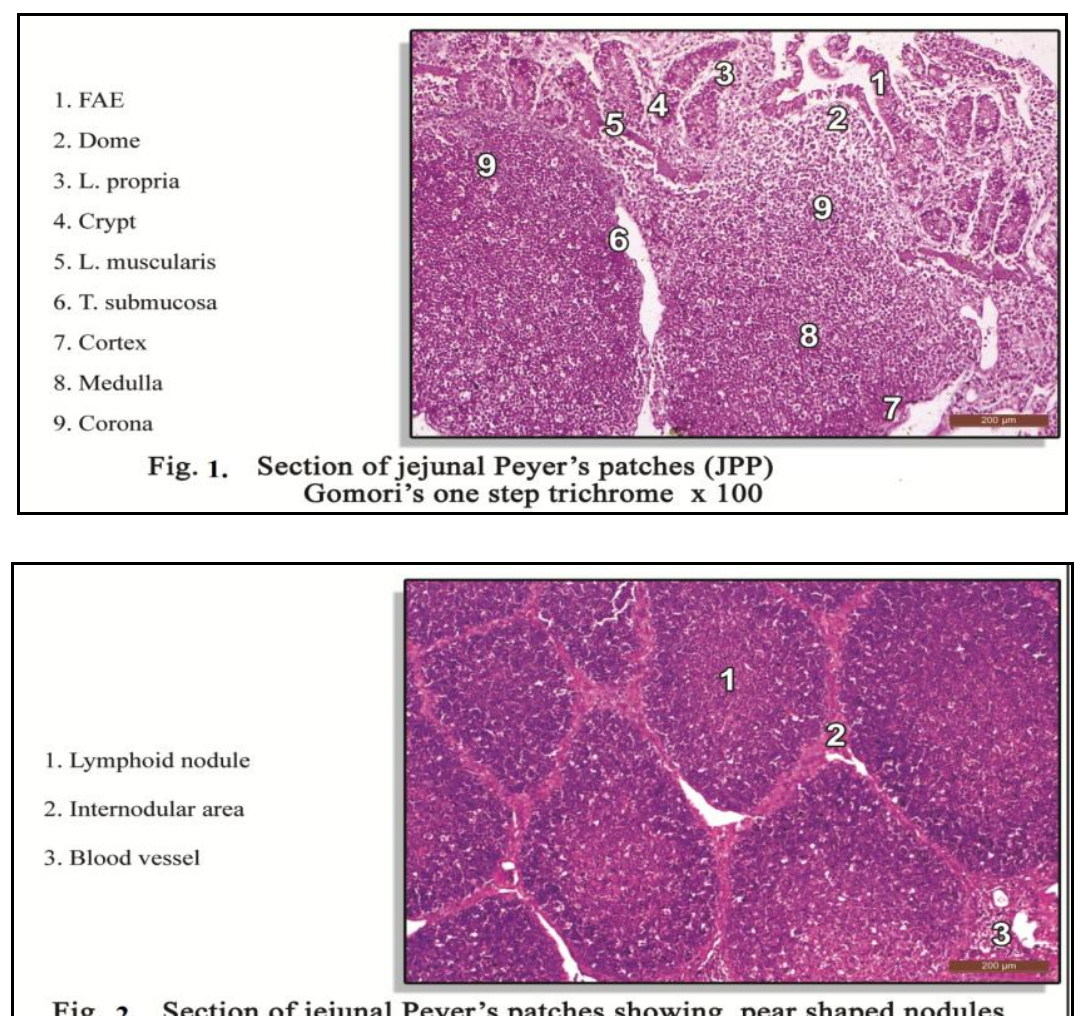

Fig. 2. Section of jejunal Peyer's patches showing pear shaped nodules H\&E $\times 100$

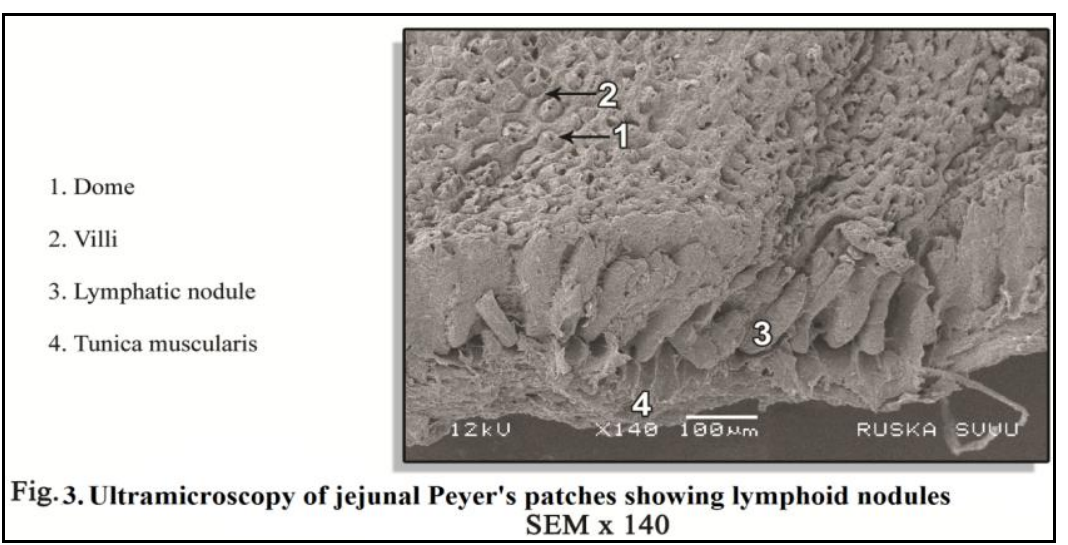




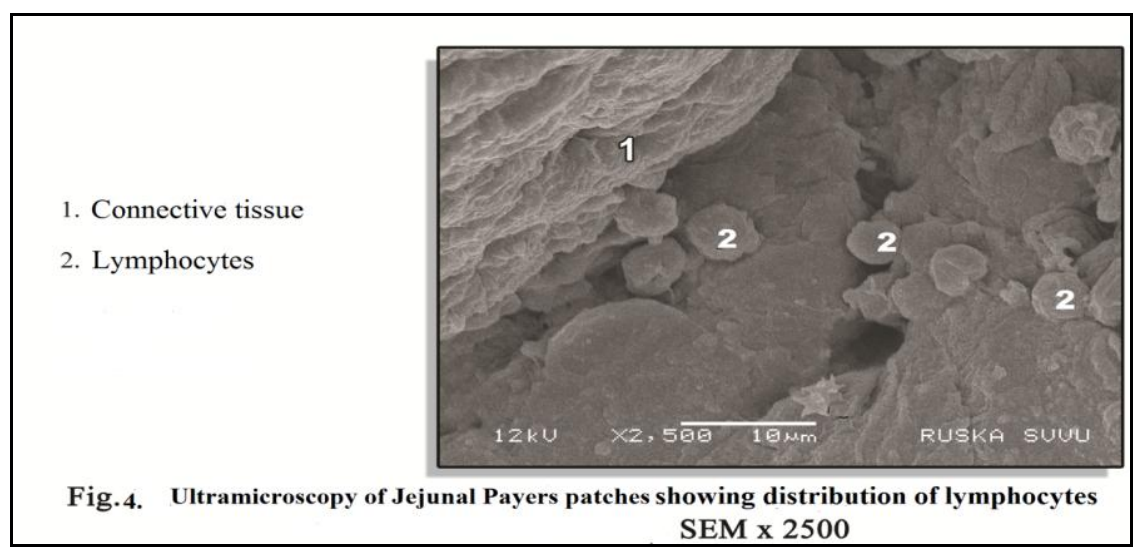

In scanning electron microscopy (SEM), of the mucosal surface of PP flattened long villi were seen fused to one another and presented a lattice appearance. In between them numerous cavities were seen which corresponded to the goblet cells. In between the villi in JPP, domes were seen with cylindrical, rounded or conical tips which bulged towards the intestinal lumen. The dome of JPP was not clearly visible due to the presence of leaf-like villi. Below the dome epithelium, long sac like follicles was seen. In the interfollicular area between the follicles large number of lymphocytes and thick bundles of collagen fibres were seen. These observations are in accordance with the findings of Saw et al., (2005) in calves (Fig. 3 $\& 4)$. The FAE cells in the dome enclosed and transported luminal macromolecules into the cytoplasm (Torres, 1981). Similar to the results of SEM studies by Prado et al., (2005), collagen fibres were seen as thick bundles forming a network of parallel layers in the submucosa. This network was denser in the interfollicular area than in the follicular area and formed a capsule surrounding the lymphoid follicles.

In conclusion the histology, scanning electron microscopy and micrometry of jejunal Peyer's patches in small intestine of goats were studied in six apparently healthy male goats of six months of age. It was observed that the lymphoid nodules in jejunal Peyer's patches remained active and continued to produce lymphocytes suggesting that it was a secondary lymphoid organ in contrast to the ileal Peyer's patches which are primary lymphoid organs.

\section{References}

Aleksandersen, M., Nicander, L. and Landsverk, T. 1991. Ontogeny, distribution and structure of aggregated lymphoid follicles in the large intestine of sheep. Dev. Comp. Immunol. 15: 413-422.

Larsen, H.J. and Landsverk, T. 1986. Distribution of $\mathrm{T}$ and B lymphocytes in jejunal and ileocaecal Peyer's patches of lambs. Res. Vet. Sci. 40: 105-111.

Liebler, E.M., Pohlenz, F. and Cheville, N. 1988. Gut-associated Lymphoid Tissue in the Large Intestine of Calves. Vet. Pathol. 25: 509-515.

Luna, L.G. 1968. Manual of Histological Staining Methods of the Armed Forces Institute of Pathology. $\left(3^{\text {rd }}\right.$ Ed.).McGraw-Hill Book Company, New York, 258p.

Reynolds, J.D. and Morris, B. 1983. The evolution and involution of Peyer's patches in fetal and postnatal sheep. European J. Immunol. 13: 627-635.

Saw, P.P., Zuki, A.B.Z., Zamri-Saad, M., Rahman, O.A. and Effendy, A.W. 2005. Morphological study of the jejunal and 
ileal patches of three month old calves. J. Anim. Vet. Adv. 4: 579-589.

Shukla, S. and Singh, G.K. 1999. Gross and histomorphology of gut-associated lymphoid tissue (GALT) in dogs. $J$. Immunol. Immunopath. 1: 76-79.

Snedecor, G.W. and Cochran, W.G. 1994. Statistical Methods. $\left(9^{\text {th }}\right.$ Ed.). The Iowa state university press, USA, 313p.

Statistical Product and Service Solutions (SPSS) Statistics for Windows, Version
21.0. Armonk, NY:IBM Corp

Tenorio, E.M.L. and Pabst, R. 2006. MALT structure and function in farm animals. Vet. Res. 37: 257-280.

Torres, M.A. 1981. Morphologic characteristics of the epithelial surface of aggregated lymphoid follicles (Peyer's patches) in the small intestine of newborn gnotobiotic calves and pigs. Am. J. Vet. Res. 42: 232-236.

\section{How to cite this article:}

Indu, V. R., K. M. Lucy, N. Ashok and Maya, S. 2020. Histology and Scanning Electron Microscopy of Lymphoid Tissue in Jejunal Peyer's Patches in Goat. Int.J.Curr.Microbiol.App.Sci. 9(11): 2305-2309. doi: https://doi.org/10.20546/ijcmas.2020.911.276 